\title{
Encontros cotidianos e a pesquisa em Educação: relações raciais, experiência dialógica e processos de identificação ${ }^{1}$
}

\section{Quotidian encounters and the research in Education: racial relations, dialogic experiences and identification processes}

\author{
Mailsa Carla Pinto Passos²
}

\begin{abstract}
RESUMO
O presente artigo consiste em uma reflexão construída no processo de uma pesquisa em Educação realizada em diálogo com o cotidiano escolar e tendo como tema as relações raciais. Esse estudo - que teve como questão principal compreender "como, no Brasil, as populações afro-brasileiras estabelecem laços e alianças culturais e identitárias" - elegeu como material de análise as enunciações e diálogos que emergem cotidianamente em contextos educativos. Discorremos aqui sobre o "encontro" como metodologia de pesquisa, fenômeno a partir do qual esses contextos emergem como ambientes polifônicos. O trabalho teve como principais interlocutores teóricos Mikhail Bakhtin e seus estudos da linguagem; Boaventura de Sousa Santos, que nos orienta na reflexão sobre as questões epistemológicas; Paul Gilroy e Stuart Hall. É uma pesquisa que dialoga ainda com o texto literário, compreendendo a literatura como teoria social.
\end{abstract}

Palavras-chave: cotidiano; relações raciais; metodologia de pesquisa; linguagem; currículo.

1 O presente artigo consiste na apresentação de alguns resultados de uma pesquisa financiada pelo Edital Universal, do Conselho Nacional de Desenvolvimento Científico e Tecnológico (CNPq); pelo Programa Jovem Cientista do Nosso Estado e pelo Programa de Apoio à Escola Pública, da Fundação Carlos Chagas Filho de Amparo à Pesquisa do Estado do Rio de Janeiro (FAPERJ).

2 Universidade do Estado do Rio de Janeiro. Rio de Janeiro, Brasil. Rua: São Francisco Xavier, n ${ }^{\circ} 524$ - Pavilhão João Lyra Filho, $12^{\circ}$ andar - Maracanã. CEP: 20550-900. 


\begin{abstract}
The present paper is a reflection built on the process of a research on the Education field. This research was conducted in dialogue with schools quotidian and had racial relations as a theme. Its main question was to comprehend "how the Afro-Brazilian population establishes identity bonds and connections". The expressions and dialogues that daily appear in educational contexts were chosen to be its analyses' material. Here the author discourses about the "encounter" as a research methodology, phenomenon from which these contexts appear as polyphonic environments. This paper's main theoretical interlocutors were: Mikhail Bakhtin and his language studies; Boaventura de Sousa Santos guiding on the reflection on epistemological matters; Paul Gilroy and Stuart Hall. It is still a research that also dialogues with literary work, understanding literature as a social theory.
\end{abstract}

Keywords: quotidian; racial relations; research methodology; language; curriculum.

Se "falar é existir absolutamente para o outro", como nos ensinou Fanon (2008), quem enuncia tem a possibilidade de escapar do lugar da invisibilidade pela/com a palavra, pelas/com as narrativas. São elas que guardam a potência das renovações e dos deslocamentos, consistindo o que emerge dessas narrativas em material rico para a compreensão da rede de significações e sentidos presentes na cultura, na sociedade. A palavra e a profusão de significados que ela guarda não pertencem a um só indivíduo, a palavra é uma ponte (BAKHTIN, 2004), produtora e produto de saberes, crenças, gostos, que circulam polifonicamente e que guardam níveis de complexidade que nos colocam "em xeque" todas as vezes que tentamos atribuir um sentido único às relações usando modos simplificadores e aprisionando os sentidos em modelos dicotomizados.

Fazer pesquisa em Educação é "encontrar o 'outro"” na dinâmica dessas "pontes". É, sabendo que a linguagem é incompletude, investir em uma escuta atenta das narrativas das experiências dos nossos interlocutores e interlocutoras, posicionando-nos dialogicamente nessa relação. Trata-se de uma perspectiva dialógica que contribui para a compreensão do cotidiano, não naquilo que ele carrega de repetição e reprodução, mas principalmente naquilo que está presente como criação anônima do "homem comum", como invenção, assim como anuncia Certeau (1994).

No estudo que desenvolvemos, no qual a principal questão é "como a diáspora africana estabelece laços e alianças culturais e identitárias" - inspirada no que já sugeriu Gilroy (2001) - e ainda "como homens e mulheres afrodescendentes são representados enquanto referência ética e estética no cotidiano 
escolar", é com a enunciação que trabalhamos, com a polifonia de vozes que circulam no ambiente escolar e que nos ensinam sobre a complexidade e as tensões que se impõem quando nos propomos a refletir sobre este cotidiano e seus praticantes.

\section{Uma criança, sua professora e a Branca de Neve: emergências no cotidiano e a questão racial}

Karoline $^{3}$ tem 5 anos e mora em uma comunidade no Bairro de Acari, na periferia da Cidade do Rio de Janeiro, no Brasil. Ela estuda em uma Escola Municipal de Educação Infantil e adora as aulas da professora Cláudia, de Educação Física. Em uma tarde, a professora acabara de realizar uma atividade lúdica com a turma de Karoline, trabalhando com o filme "Kirikou e a feiticeira", de Michel Ocelot ${ }^{4}$. A escolha do filme se deu porque a educadora desejava discutir com as crianças a ideia de um "herói minúsculo" - "o mais fraco", que reverte a situação a seu favor, vencendo "o mais forte" e discutir a representação da criança negra como um herói. O filme conta a história de um menino que tem seus poderes potencializados exatamente pela sua condição de ser pequeno. $\mathrm{O}$ protagonista é Kirikou, criança de uma tribo da África Ocidental, que consegue vencer uma feiticeira que ameaçava seu povo.

A menina Karoline gostou tanto do trabalho que foi desenvolvido pela professora neste dia, e além disso gostava tanto da "Tia Cláudia", que a abraçou carinhosamente e lhe disse "Tia, você é muito linda! Você é a Branca de Neve!"

$\mathrm{O}$ elogio, ao mesmo tempo em que encanta a professora, provoca uma série de reflexões e deflagra para ela questões que dizem respeito aos modelos/ referências que uma criança negra de cinco anos tem em seu cotidiano. Como se forma a subjetividade de uma menina negra em um país da América Latina, cuja população de indivíduos negros autodeclarada, segundo o último censo do IBGE, passa de 50\%? Que imagens, que referências fazem para do cotidiano dessa criança?

3 Neste texto foram preservados os nomes das pessoas. Optei por fazer desta forma por entender que a pesquisa não desqualifica nem expõe de maneira vexatória nenhum sujeito em nosso estudo. A todos - inclusive às crianças - foi perguntado durante o trabalho na escola se poderíamos manter seus nomes nas publicações oriundas da pesquisa, ao que responderam positivamente.

4 "Kirikou e a Feiticeira" (Kirikou et la Sorciére), de 1998; animação escrita e dirigida por Michel Ocelot; produção: Bélgica/França/Luxemburgo. 
As questões que emergem a partir deste "encontro" vão ser discutidas na dissertação de mestrado da Professora Cláudia Queiroz, De uma chuva de manga ao funk de Lelê: imagens da afrodiáspora em uma escola de Acari, defendida em 2011.

O fato é que a menina Karoline, a professora Claudia e a maioria das crianças dessa escola são "indivíduos de melanina acentuada e cabelos crespos", como grande parte da população daquela região do Rio de Janeiro. Por isso o sentimento ambíguo da professora quando recebe o elogio carinhoso da aluna.

O cenário que compõe o acontecimento narrado vale a pena ser descrito, pois é fundamental para a discussão que aqui propomos. No pátio dessa escola, em um grande painel, está pintada a personagem de Branca de Neve e dos Sete anões, como representou Walt Disney, apropriando-se do conto popular europeu, e como Hollywood celebrizou em 1937.

Mobilizada então por este acontecimento, a professora começa a reparar em seu entorno, e começa a observar com mais atenção também os desenhos que ilustram as porta dos banheiros da escola - distinguindo o dos meninos do das meninas. Observa também os desenhos que ilustram o diário de classe e vê que todas essas ilustrações são de crianças louras, muito louras, de um amarelo vivo que na verdade não representam nem as crianças que frequentam aquela escola nem ninguém, pois é impossível encontrar qualquer pessoa cujos cabelos sejam tão amarelos e os traços tão estereotipados quanto os dessas representações.

Mas por que será que esses desenhos continuam a ser usados mesmo que não se pareçam com ninguém? Mesmo que não identifiquem ninguém naquele cotidiano? Minha hipótese é que muitas vezes naturalizamos que essas imagens nos representam mesmo que sejam muito estranhas a nós.

Não somente a circulação, mas o lugar de destaque que essas imagens ocupam em algumas escolas confirma o que sugere Santos (2010), em relação ao conhecimento e à produção de uma "não existência". Nas sociedades contemporâneas se estabeleceu um "pensamento abissal", um modelo de pensamento que está fundamentado em "distinções visíveis" e "distinções invisíveis", sendo as primeiras garantidas e explicadas pelas últimas. As distinções invisíveis instituem-se através de uma linha que divide a realidade social em dois universos: aquilo que existe e o que é produzido como não existência.

O pensamento abissal se sustenta na impossibilidade da copresença entre os dois lados da linha. A visibilidade dos sujeitos - seus conhecimentos, suas

5 Em relação à expressão "melanina acentuada" ver em Namíbia, não!, texto teatral do dramaturgo baiano Aldri Anunciação, ganhador do prêmio FAPEX de Teatro de 2010, na Bahia. No texto, em um ambiente futurista, no Brasil, o governo baixa um decreto a partir do qual toda pessoa de "melanina acentuada", ou seja, afrodescendente, terá que ser deportada para o país africano de seus ancestrais. 
práticas, seus corpos -, de um dos lados da linha, assenta-se na negação daquilo que está do outro lado.

Penso que os processos de socialização das populações afrodescendentes na sociedade brasileira constituem um exemplo de como ocorre essa produção da não existência a que se refere Santos (2010).

Como já afirmamos, os negros autodeclarados são hoje a metade da população brasileira segundo os últimos dados do IBGE e as políticas de distribuição de terra, de acesso às universidades, de democratização da educação como um todo e visibilização desses grupos e suas práticas na mídia são relativamente recentes e ainda bastante incipientes.

E como esta não existência se produz? Bem, aqui vale a pena lembrar que historicamente tanto os discursos científicos quanto o jurídico contribuíram para a ideia de uma não existência dessas populações no Brasil.

Mas é ainda Santos (2010) quem indica alguns caminhos para compreender essa produção. A não existência não somente é produzida mas também garantida em primeiro lugar quando defendemos um saber único, no caso o conhecimento científico; quando defendemos uma história única; quando naturalizamos sem discussão as hierarquias no campo da cultura, quando defendemos um único padrão estético; e por último quando defendemos uma lógica produtivista (o que não é produtivo não nos serve).

É possível dizer que são poucos os heróis negros no Brasil hoje, pelo menos no campo das ciências e das artes, representados como aqueles que contribuem para o desenvolvimento da nação. Embora eles estejam presentes na história, é ainda necessário contá-la a contrapelo (BENJAMIN, 1994) para que as narrativas "sobre eles" e "com eles" emirjam. Esses grupos foram historicamente invisilibilizados como referência ética e estética.

Exemplos que ilustram a produção dessa invisibilidade são os casos em que, se existe um afro-brasileiro que seja referência, ele é representado como branco. ${ }^{6}$ Isso consiste em um processo histórico. A socialização das populações sequestradas da África durante o período escravista para servirem à economia agrícola no Brasil tem sido marcada pela exclusão e pelo preconceito.

O racismo no Brasil é um "preconceito de marca", como nos ensina Nogueira (1955). Nesse tipo, o fenótipo e a aparência racial determinam o grupo que é alvo da discriminação. Em nosso país o racismo segue este pa-

6 Uma propaganda da Caixa Econômica Federal, veiculada recentemente, em 2011, cujo homenageado era Machado de Assis - um escritor brasileiro canônico do século XIX, que era negro - tinha como ator que representava o escritor um homem branco. Depois de muitos protestos por parte da sociedade civil organizada, os realizadores da propaganda mudaram o ator. Este ocorrido nos dá pistas de como o pensamento abissal e as tais linhas que invisibilizam uns em detrimento de outros se estabelecem. 
drão, manifestando-se de variadas formas, frequentemente dissimuladas pelo constrangimento da sociedade brasileira em ver explicitado o seu preconceito, ou falar dele. Temos "preconceito de ter preconceito" (FERNANDES, 2007), mas o racismo existe e, dissimuladamente ou não, produz subjetividades. Uma das formas como ele tem se manifestado tem sido essa produção dos sujeitos afro-brasileiros e de suas práticas como "não existência".

As referências, tanto éticas quanto estéticas, estão pautadas por uma "branquitude", que, apesar de consistir mais em um modelo a ser perseguido do que propriamente em uma realidade, em função da circularidade de discursos e práticas, acaba tornando-se real: tomemos como exemplo a recorrente imagem dos afro-brasileiros vinculada à subalternidade, à vitimização e à escravidão, ou à marginalidade. ${ }^{7}$

A branquitude é a norma-cidadã, o que é diferente desta normatividade está maculado pelo, em alguns casos, desconfortável lugar do "diferente". Digo "desconfortável" porque aqui neste caso o diferente é classificado hierarquicamente. Liv Sovik nos chama a atenção para o fato de que no Brasil a branquitude é "prática e lugar social", cujo valor "se realiza na hierarquia e na desvalorização do negro", mesmo quando o conceito raça não está explicitado (SOVIK, 2009, p. 34).

No episódio que narramos, protagonizado por Karoline e sua professora, o conceito de raça também não está explicitado, entretanto não há como ignorar os discursos que criaram a categoria e que a perpetuaram como exclusão e preconceito, mesmo que "não ditos". Karoline gostou tanto da atividade com a história de Kirikou, e gosta tanto da professora, que seu elogio não pode ser analisado sem uma especial atenção para os sentimentos ambivalentes e complexos que envolvem seu discurso: a ideia de uma branquitude como referência estética e o deslocamento da imagem da professora de quem gosta tanto para este lugar.

7 Obviamente isso foi uma construção histórica. No final do século XIX, no Brasil, com o fim do período escravista, essas populações foram retiradas da condição de escravo sem políticas públicas de inclusão social. Junta-se a isso os discursos da ciência da época - já referidos aqui nesse texto - que ensinavam que os negros eram uma raça inferior e garantiam que a tendência da "raça inferior" era sucumbir com o passar do tempo. Estes e tantos outros identifico como manifestações do pensamento abissal, e contribuíram para a construção das representações dos afro-brasileiros como circulam contemporaneamente. Para confirmar isto, há uma profusão de exemplos. Um deles é a cartilha "Previna-se contra furto e roubo a pedestre na Rodoviária", que foi confeccionada pelo destacamento da Polícia Militar na Câmara dos Deputados e distribuída na rodoviária e no metrô de Brasília, capital do Distrito Federal do Brasil. Nela, o desenho mostra dois assaltantes negros, de arma em punho, interpelando um homem branco, vestido de terno e gravata. É impossível não observar o quanto essa representação está inserida em uma linhagem discursiva e o quanto produz de outros tantos discursos cujos sentidos seguem na mesma direção. Ver isto em: <http://www. viomundo.com.br/denuncias/policia-militar-do-df-assaltantenegro-vitimabrancoederal-assaltantenegro-vitimabranco.html>. 
Desse acontecimento cotidiano sobreveio uma série de questionamentos sobre os processos identitários de crianças negras e sobre as referências estéticas que circulam nos ambientes educativos e fora deles. Foi a partir desse episódio que começamos a ver o quanto são necessários estudos sobre os processos identitários e suas relações com a linguagem e com as práticas, em diálogo com a infância. Estudos que não tenham a perspectiva da criança como um porvir, a preocupação de "formar" as crianças para um futuro idílico, sem racismo e sem tensões sociais, trabalhos que sejam movidos pelo desejo de compreender como se manifestam essas questões em ambientes pelos quais as crianças circulam e nos quais elas se "encontram" com os adultos, sujeitos sociais, praticantes do cotidiano, que nos ensinam sobre a sociedade e suas questões.

O trabalho que desenvolvemos a partir do que provocou este "encontro" entre Karoline e a professora Cláudia foi contar outras histórias - muitas delas silenciadas - e compartilhá-las com as crianças dessa escola, tentando escapar dos "Perigos de uma história única", como nos avisa Chimamanda Adichie 8 , investindo na escuta atenta em relação à pluralidade de histórias que foram silenciadas pela versão hegemônica da História. Tendo inclusive uma especial atenção às emergências de sentidos, de pontos de vista, de deslocamentos identitários que aconteceram a partir daí.

\section{Contribuições do "encontro" para a produção do conhecimento: discurso na vida e na literatura}

No caso da escola aqui referida, um conjunto de atividades foi organizado para fomentar discussões com as crianças sobre suas práticas e seus processos identitários, sempre problematizando a "branquitude" como referência na sociedade, na tentativa ainda de interferir no currículo formal, inserindo na escola personagens/heróis afro-brasileiros como referências éticas e estéticas. Mas havia outro critério. O trabalho pressupunha uma ideia de herói diferente do modelo ocidental moderno. Um critério importante era que esses heróis/ heroínas fossem sujeitos do cotidiano, que se parecessem com as mães, pais, avós e irmãos das crianças.

Para isso, trabalhamos com diferentes linguagens, com a literatura, a música, formas de arte diversas, entendendo a arte como prática/linguagem

8 Quanto à fala de Chimamanda Adichie, escritora nigeriana, sobre "Os perigos da história única" ver em: $<$ http://www.ted.com/talks/lang/por_br/chimamanda_adichie_the_danger_of_a_ single_story.html>. 
mediadora de sujeitos. Tanto as mediações quanto os diálogos são categorias bastante significativas na pesquisa que desenvolvemos.

Porque é desses/nesses momentos de "encontro" que laços e alianças se estabelecem, práticas e saberes produzidos como não existência - junto com seus praticantes - emergem.

Entendemos o encontro, na pesquisa em Ciências Humanas e Sociais, como uma experiência de interação entre sujeitos, que pode ser produzida/ organizada/promovida pelo pesquisador, ou pode se dar ao acaso. Ao longo dos trabalhos desenvolvidos foi possível observar que no processo da pesquisa acontecem encontros entre sujeitos que vão suscitar outros encontros e outros encaminhamentos para a produção do conhecimento.

Esses têm consistido em terreno fértil para pensar conceitos, provocando discussões e alimentando nossa produção no grupo. Interpretar o movimento dialógico pelo qual passam nossos interlocutores e nós mesmos tem sido uma experiência importante na formação dos pesquisadores que participam do grupo. A emergência de saberes, de relações, de narrativas é grandiosa no momento em que um sujeito "é afetado pelo outro" e que este "afetar-se" gera conhecimento. Esses encontros assim têm significado experiência no sentido daquilo que "nos afeta", que "nos modifica" (BENJAMIN, 1994; LARROSA, 2002), modificando nossas práticas e nossa linguagem. Esse compartilhamento da experiência deflagra mudança de comportamento e de pontos de vista em ambas as partes, fazendo o sujeito ressignificar o outro na mesma medida em que se ressignifica. Este é nosso critério: para nomear um contato entre sujeitos de "encontro" no processo da pesquisa, é preciso que esse "deixar-se afetar pelo outro" aconteça e que isso se transforme em linguagem. Desta forma, aqueles sujeitos que foram produzidos como "não existência" (SANTOS, 2010) passam a existir neste momento, para o outro e para si, através da palavra, produtora/promotora de sentidos e de realidades (BAKHTIN, 2004). O encontro é ali onde emerge a alteridade, "o interlocutor que nos habita". Ao nos darmos conta do "outro", ele passa a existir naquilo que enunciamos, no nosso discurso (BAKHTIN, 1981).

Outra observação importante que é preciso ser feita em relação ao que temos denominado de "encontro" como uma metodologia de pesquisa é que este "encontrar" não significa relação harmoniosa, idealizada ou falsamente esvaziada de conflitos e tensões.

Na língua inglesa existem pelo menos duas palavras que significariam "encontrar", que são o verbo "to meet" e o "to find". ${ }^{9}$ Alguns dos sentidos do primeiro verbo são "encontrar-se, travar conhecimento, reunir-se, ajuntar-se, agrupar-se".

9 Disponível em: < http://michaelis.uol.com.br/moderno/ingles/definicao/ingles-portugues/ find\%20_449513.html $>$. 
Já "to find" significaria achar, encontrar, descobrir. O encontro a que me refiro - que é a experiência que temos vivido na pesquisa - aproxima-se mais dos significados de "to find" do que de "to meet". "To find" é encontrar algo que não havia, que está sendo descoberto a partir de uma procura, de uma busca do que não existia - as "emergências" do que foi produzido como "não existência", como ausência. Isso é que emerge da polifonia presente no universo social. E como se trata de um processo polifônico, "encontrar-se" como outro nem sempre é harmonioso e esvaziado de conflitos. Muito pelo contrário, acontece em uma zona de conflito.

\section{De uma experiência particular: a literatura e algumas pistas de como acontecem os encontros}

A literatura tem contribuído significativamente na produção teórica da pesquisa. Compreendemos o texto literário como uma forma de teoria social. Compartilhamos com Bakhtin e Voloshinov a ideia de que arte e vida são formações sociais que se afetam mutuamente. Por isso, em muitos momentos a literatura é mais uma possibilidade de diálogo.

Como exemplo temos o conto de Chimamanda Adichie, A private experience $^{10}$, história na qual duas mulheres nigerianas refugiam-se em um armazém abandonado após escapar de um conflito religioso entre católicos e mulçumanos. Neste encontro, as duas personagens cujas diferenças são aparentemente inegociáveis - já que pertencem a etnias, religiões e classes sociais diferentes - compartilham o medo, a sensação de abandono e o sentimento de amizade.

As diferenças entre as duas são muitas: a camiseta estampada com a imagem da estátua da liberdade da estudante católica, em contraposição à wrapper ${ }^{11}$ que veste a mulher mulçumana, por exemplo. Mas o fato de pertencerem a dois universos totalmente distintos, de terem histórias completamente diferentes não impede que elas vivam naquele armazém abandonado um intenso processo de identificação.

O armazém torna-se um "tempoespaço" a ser dividido solidariamente pela mulçumana de origem hausa e a cristã igbo. Solidariedade esta que é experimentada em função de uma contradição: elas estão reunidas e confinadas

10 Este conto foi traduzido para o português para o nosso grupo de pesquisa para fins didáticos por Nelson Santiago.

11 Uma saia de tecido de algodão cujo tecido é enrolado no corpo em várias voltas. 
àquele espaço, pois seus grupos étnicos não conseguem conviver dividindo o mesmo território. É a impossibilidade de convivência dos dois grupos em um mesmo território que as confina ali, onde a experiência da diferença funda a dialogicidade.

A wrapper que a mulçumana estende no chão empoeirado do armazém para que possam sentar-se é o símbolo de que é possível as duas colocarem-se no mesmo plano:

Ela desamarra sua wrapper verde, que cobre todo o seu corpo, e a estende no chão empoeirado. [...]

- Vem e senta!

Chika olha para o tecido gasto estendido no chão [...]

- Não, sua wrapper vai sujar.

- Senta. Nós vamos esperar aqui muito tempo.

É a wrapper, transformada em tapete, que as acomoda, as coloca em condições simétricas. É ali - ao sentar neste restrito pedaço de tecido estendido no chão - um microcosmo de identificações e memórias - que a vendedora de cebolas mostra a Chika os seios inflamados por causa do tempo em que está longe do filho que amamenta, e que a estudante de medicina lhe sugere como cuidar dos mamilos feridos; é ali que ela chora a preocupação com a filha que vendia castanhas quando se perdeu na confusão das ruas por causa dos conflitos; é ali que a companheira de infortúnio emociona-se com a sua preocupação.

Poderíamos fazer pelo menos duas observações sobre essa experiência do encontro narrado por Adichie: primeiramente o fato de haver uma busca de identificação entre as duas, quando a enunciação da diferença dá lugar à enunciação da experiência comum. É quando Chika chega a mentir sobre o fato de sua mãe ter tido também uma infecção nos mamilos depois de ter muitos filhos, só para sua história parecer mais próxima da história da vendedora.

- O mesmo aconteceu com minha mãe. Os seios dela racharam com a chegada da sexta criança.

Apesar de quase nunca mentir, Chika o faz ali e tem um propósito: procurar uma experiência comum que promova uma identificação. 
- O que sua mãe passa no mamilo dela?

- Manteiga de cacau. As rachaduras curaram rápido.

Depois, chama-nos a atenção o fato de que essa busca de identificação não aconteça sem momentos de tensão. Este processo não é harmônico. Quando Chika pergunta sobre com qual filho a vendedora está preocupada, já tendo ela respondido isso anteriormente, isso a deixa irritada por não estar sendo "ouvida".

- O bebê? - Chika soube o quanto a pergunta soava estúpida no momento em que a fazia.

A mulher balança a cabeça com impaciência, até mesmo com uma certa raiva nos olhos. - Você tem problema de ouvido? Você não escuta o que digo?

- Desculpe - Chika diz.

- O bebê está em casa! Esta é a primeira filha, Halima. E a mulher começa a chorar.

Esta passagem nos dá pistas daquilo que afirmamos anteriormente sobre o fato de que o encontro não é sempre harmonioso. Todo encontro pressupõe também tensão, é sempre polifônico, naquilo que a polifonia pressupõe de contraponto de vozes (BAKHTIN, 1981, p. 193).

No conto, uma mulher é o contraponto da outra, uma é a orientação dialógica da outra, o que só pode existir daquela forma naquele contexto que elas dividem, mas sem dicotomizações. Elas são apresentadas na relação.

Esta narrativa nos ajuda a pensar que o encontro, como procedimento teórico-metodológico, não é qualquer um que se dá em qualquer lugar. A cada experiência corresponde um contexto. O que torna essa "experiência narrável" (BENJAMIN, 1994) é o contexto que lhe atribui sentido. O contexto dá sentido às relações.

Para existir encontro é necessário que haja uma experiência compartilhada, um chão comum da linguagem (BAKHTIN, 2004) e que esta experiência produza narrativas, consista em uma "experiência narrável", e engendrem alguma experiência relacionada à vida prática cotidiana (BENJAMIN, 1994).

Essa experiência não é somente o vivido convertido em narrativa. Não se trata de dois fenômenos distintos, mas sim de uma única coisa: a experiência só faz sentido quando narrada; narrar é viver, na medida em que narrar é dar-se conta do vivido. 
$\mathrm{Na}$ experiência do encontro das duas mulheres, ao narrar como se perderam das pessoas queridas em meio aos conflitos da rua - uma da irmã e a outra da filha mais velha - emergem na narrativa passagens e situações que dividiram com estes entes queridos; as lembranças dos momentos em que estiveram em sua companhia. Dividem a preocupação com o desaparecido da outra. Narrar a perda tem a função de aproximá-las. A dor e a perda, uma vez narradas, vão produzir processos de solidarização.

É esse tipo de narrativa que tem nos interessado nas pesquisas: aqueles discursos que, ao produzir realidade, produzem também processos de solidarização. Refiro-me aqui às narrativas do tipo solidário para as quais Martins (2012) nos chama a atenção. A autora vai descrever a narrativa solidária como sendo a

perspectiva criadora de um elo de solidariedade entre autor, narrador e leitor, engendrando, desse modo, o que chamamos de narrativas solidárias. Algo próximo do que o historiador Thomas W. Laqueur chama de narrativas humanitárias: textos, cuja temática e forma de abordá-la contribuem para suscitar "paixões solidárias" (MARTINS, 2012, p. 58).

Cremos também que é possível manter na pesquisa o caráter solidário da narração do "outro". Cria-se um envolvimento entre os pares implicados uns com os outros pela experiência comum forjada no jogo social e na dinâmica da interação verbal. É na experiência humana que arte, vida e ciência se unificam (BAKHTIN, 2003). Eu diria ainda que é na arte, na vida e na ciência, como práticas, que é possível compartilhar a experiência de ser humano. Esses são os caminhos que nossas pesquisas têm trilhado: os da experiência do encontro como fenômeno gerador de uma identificação entre as partes e uma mudança no modo de ver tanto ao outro como a si mesmo.

\section{Encontro com Magdalena Santos: experiência estética, experiência ética}

Conhecemos a artesã e artista plástica Magdalena Santos quando sua filha entrou para o grupo de pesquisa, em 2006.

A professora Sonia Regina dos Santos, filha de Magdalena, havia terminado o curso de Letras, fazia especialização em Literatura Africana, enquanto preparava o projeto para ingressar no Mestrado em Educação. 
Magdalena é uma senhora septuagenária, afro-brasileira, artesã, que trabalhou toda a vida como empregada doméstica e se aposentou nessa condição. Após a aposentadoria, matriculou-se em um curso de pintura, segundo ela mesma, para manter-se ativa e encontrar outras pessoas.

Pelo menos na Região Sudeste do Brasil é muito comum encontrarmos cursos nos quais mulheres das mais variadas faixas etárias inscrevem-se para aprender determinadas técnicas de pintura em tela. São cursos que trabalham com um modelo a ser reproduzido pelo aluno e frequentemente os modelos são naturezas mortas: variedade de flores e/ou frutas representados em jarros, fruteiras, ambientes domésticos.

Em casa - onde Magdalena, depois de ficar viúva, vive com as filhas e uma neta - as conversas sobre as origens de sua família e em torno das memórias e da história de seus ancestrais, puxadas muitas vezes por Sonia começam a ser uma constante, já que ela desenvolvia pesquisa sobre as narrativas de mulheres afro-brasileiras e os diálogos das crianças da escola pública com esta literatura.

Pouco a pouco, muito em função dos assuntos que começam a circular em casa provocados pelos estudos da filha, Magdalena começa a pintar telas não somente representando natureza morta. Seus quadros assumem a temática da história de "seu povo e sua família", como ela mesma diz. Começa a pintar suas memórias, cenários da sua infância, ela mesma e seus familiares, assumindo em sua obra a valorização dessa temática, de cuja importância até então nem ela mesma havia se dado conta.

Em função das conversas em casa com a filha Sonia e do encontro com o grupo, ela começa a assumir a identidade de artista plástica, coisa que ela sempre foi mas não se dizia. Não havia um sentimento de legitimidade por parte dela neste lugar. Este sentimento de pertença só começou a existir quando um "outro" - neste caso o nosso grupo - apontou para ela o que ela não via. Isso se deu não só porque estávamos na universidade realizando pesquisa sobre a arte como mediadora das relações entre os sujeitos e seus processos identitários, mas porque, com nosso "excedente de visão" sobre ela, víamos o que Magdalena não conseguia ver sobre si mesma.

Isto acaba confirmando que

O excedente de visão é o broto em que repousa a forma e de onde ela desabrocha como uma flor. Mas para que esse broto desabroche na flor na forma concludente, urge que o excedente de minha visão complete o horizonte do outro indivíduo contemplado sem perder a originalidade deste. Eu devo entrar na empatia com esse outro indivíduo, ver axiologicamente o mundo de dentro dele tal qual ele vê, colocar-me no 
lugar dele e, depois de ter retornado ao meu lugar, completar o horizonte dele com o excedente de visão que desse meu lugar se descortina fora dele. (BAKHTIN, 2003, p. 23).

A imagem que temos de nós mesmos é sempre incompleta e parcial. Quem nos dá o "acabamento" é o "outro". Aquele que tem o excedente de visão sobre mim, sobre quem eu sou - e ainda sobre minhas práticas e meu pertencimento. Avaliamo-nos para o outro e através do outro, e não para nós mesmos. (BAKHTIN, 2003).

Existe em nosso encontro com Magdalena um processo de negociação. A artista começa a pintar não somente para ela, mas também para um "auditório social", que somos nós. Seus quadros enunciam o que é demandado por esse auditório: sua história, sua família.

Ocorreu que nosso diálogo com Magdalena implicou-a no nosso projeto de pesquisa. Este diálogo a fez ver de outra maneira suas memórias e sua história, provocando-a a colocar-se no lugar de referência ética e estética, como a víamos. Sua obra consiste em um diálogo com os estudos de literatura afro-brasileira da filha; com a nossa pesquisa; com o que pensamos sobre seu trabalho.

Entretanto, seria ingênuo de nossa parte pensar que foi somente ela que se deixou afetar por essa experiência. Nós também fomos afetados pelo encontro com Magdalena; também nos modificamos no encontro com ela e o exemplo maior disso é a nossa percepção da potência da experiência do encontro, como desenvolvemos aqui neste artigo. Isso só nos foi possível pensar - e sentir porque Magdalena assim nos mostrou. Nesse processo, afetamo-nos todos nós. O deslocamento de se colocar no lugar do outro para ver o mundo tal qual ele vê modifica tanto aquele que se desloca como o seu entorno.

Paralelamente ao crescimento da produção da pintora - tendo ela inclusive construído um ateliê para trabalhar e guardar seus quadros -, decidimos incluí-la em nossa pesquisa em duas frentes: 1) realizar com ela um vídeo "Magdalena: a imaginação também é minha" - no qual ela fala de sua pintura e da sua vida; 2) promover o encontro de Magdalena e sua obra com crianças das escolas públicas com que temos trabalhado. Uma dessas escolas é aquela em que estuda Karoline.

Quando investimos na produção científica em Educação como um campo de possibilidades e emergências, é possível encontrar zonas de identificação nas diferenças, compreender crianças negras da periferia como sujeitos sociais, mulheres afro-brasileiras como referências éticas e estéticas. Para isso é fundamental colocar-se no lugar de "mais um" neste processo de conhecimento. Mais do que saber falar sobre o "outro", é importante o pesquisador saber ver/ouvir/ 
sentir, buscando narrar solidariamente seus interlocutores. Não porque este outro precisa de nós, não só pelo ofício de produzir conhecimento, mas porque para estarmos melhores em um mundo melhor precisamos deles.

\section{REFERÊNCIAS}

ADICHIE, C. N. A private experience. In: The thing around your neck. Londres: Fourth Estate, 2009.

ARENDT, H. A condição humana. Rio de Janeiro: Editora Forense Universitária, 1993.

BAKHTIN, M. Problemas da poética de Dostoiévski. Rio de Janeiro: Editora Forense Universitária, 1981.

BAKHTIN, M. Estética da criação verbal. São Paulo: Martins Fontes, 2003.

BAKHTIN, M. (VOLOSHINOV, V. N.). Marxismo e filosofia da linguagem. São Paulo: Hucitec, 2004.

BENJAMIN, W. Magia e técnica, arte e política. São Paulo: Brasiliense, 1994.

CERTEAU, M. A invenção do cotidiano: artes do fazer. Petrópolis: Vozes, 1994.

FANON. F. Pele negra, máscaras brancas. Salvador: EDUFBA, 2008.

FERNANDES, F. O negro no mundo dos brancos. São Paulo: Global, 2007.

GILROY P. O Atlântico negro: modernidade e dupla consciência. São Paulo: Editora 34; Universidade Cândido Mendes - Centro de Estudos Afro-Asiáticos, 2001.

LARROSA, J. Notas sobre a experiência e o saber da experiência. Revista Brasileira de Educação, ANPED, n. 19, jan./abr. 2002.

MARTINS, G. Pequena história literária da infância pobre. Tese (Doutorado em Literatura Brasileira) - Programa de Pós-Graduação em Letras Vernáculas - Universidade Federal do Rio de Janeiro (UFRJ). Rio de Janeiro, 2012.

NOGUEIRA, O. Preconceito de marca e preconceito de origem: sugestão de um quadro de referência para a interpretação do material sobre relações raciais no Brasil. In: BASTIDE, R.; FERNANDES, F. Relações raciais entre negros e brancos em São Paulo. São Paulo: Anhembi, 1955.

QUEIROZ, C. A. De uma chuva de manga ao Funk de Lelê: imagens da afrodiáspora em uma escola de Acari. Dissertação (Mestrado em Educação) - Programa de Pós-Graduação em Educação da UERJ. Rio de Janeiro, 2011. 
PASSOS, M. C. P. Encontros cotidianos e a pesquisa em Educação: relações raciais...

SANTOS, B. de S. A gramática do tempo: para uma cultura política. São Paulo: Cortez, 2008.

SANTOS, B. S. Para além do pensamento abissal: das linhas globais a uma ecologia de saberes. In: MENESES, Maria Paula; SANTOS, Boaventura de Sousa. Epistemologias do Sul. São Paulo: Cortez, 2010.

SOVIK, L. Aqui ninguém é branco. Rio de Janeiro: Aeroplano, 2009.

VOLOSHINOV, V. N.; BAKHTIN, M. Discurso na vida e discurso na arte: sobre poética sociológica. In: Freudianism. A marxist critique. New York: Academic Press, 1976. (Tradução de Cristóvão Tezza para uso didático).

Texto recebido em 16 de setembro de 2013. Texto aprovado em 22 de outubro de 2013. 